\title{
Correction to:"Did My Child Sleep Today?": Communication Between Parents and Educators in Early Childhood Education and Care Settings
}

\section{Candice Oakes $^{1,2} \cdot$ Sally Staton ${ }^{2} \cdot$ Sandra Houen $^{2} \cdot$ Emma Cooke $^{2}$. Cassandra Pattinson ${ }^{3} \cdot$ Sue-Lynn Teo ${ }^{1} \cdot$ Karen Thorpe ${ }^{1,2}$}

Published online: 24 October 2019

(c) Springer Science+Business Media, LLC, part of Springer Nature 2019

\section{Correction to: Child \& Youth Care Forum https://doi.org/10.1007/s10566-019-09527-3}

The original version of the article was unfortunately published without displaying the blinded contents.

The following 5 "Blinded" parts need to be amended:

1. In section "Sample", change "[BLINDED]" to "The Sleep in the Early Years Study" so it reads "...examining sleep practices in ECEC services: The Sleep in the Early Years Study."

The original article can be found online at https://doi.org/10.1007/s10566-019-09527-3.

Karen Thorpe

k.thorpe@uq.edu.au

Candice Oakes

c.oakes@uq.edu.au

Sally Staton

s.saton@uq.edu.au

Sandra Houen

s.houen@uq.edu.au

Emma Cooke

e.cooke@uq.edu.au

Cassandra Pattinson

cassie.pattinson@nih.gov

Sue-Lynn Teo

yizhen.teo@connect.qut.edu.au

1 School of Psychology and Counselling, Queensland University of Technology, Brisbane, Australia

2 Institute for Social Science Research (ISSR), The University of Queensland, UQ Long Pocket Precinct, 80 Meiers Rd, Indooroopilly, QLD 4068, Australia

3 National Institute of Nursing Research, National Institutes of Health, Bethesda, USA 
2. Under the same section "Sample", change "[blinded]" to "Brisbane" so it reads "....selecting by broad geographical distance from the Brisbane city..."

3. In section "Analysis", change "(blinded for review)" to "(CO and KT)" so it reads "Two authors (CO and KT) independently coded all of the parent...."

4. In section "Ethical Approval", change "[BLINDED]" to "Queensland University of Technology" so it reads "Ethical approval was received for the project by the Queensland University of Technology University Human Research Ethics Committee..."

5. In section "Ethical Approval”, change "(approval number: BLINDED)" to "(approval number: 1500001089)".

Publisher's Note Springer Nature remains neutral with regard to jurisdictional claims in published maps and institutional affiliations. 